\title{
A general method for the determination of the entrainment in fluidized beds
}

\author{
J Fuchs*, JC Schmid, F Benedikt, \\ AM Mauerhofer, $\mathbf{S}$ Müller, H Hofbauer \\ TU Wien, ICEBE, Getreidemarkt 9/166, 1060 Wien
}

\begin{abstract}
The measurement of the entrainment is complicated in a hot fluidized bed. Therefore, the entrainment or cycle rate of the total bed material inventory is typically estimated via mass and energy balance for e.g. the sorption enhanced reforming process. The sorption enhanced reforming process is an advancement of the conventional dual fluidized bed steam gasification process. It aims for the production of a hydrogen-rich product gas. The process is highly depends on bed material cycle rate, respectively bed material entrainment. Only limited knowledge about simple modelling methods of the entrainment of a fluidized bed are available to validate the cycle rate calculated by mass and energy balances. Therefore, measurements of the bed material entrainment at two different plants were conducted and a model based on easily accessible parameters for the entrainment of fluidized bed risers is presented. It is also verified, that the results from mass and energy balances fit well with the measured data for the entrainment.
\end{abstract}

\section{INTRODUCTION}

An important parameter for the operation of fluidized beds is the solids entrainment. Especially for coupled fluidized beds like the dual fluidized bed (DFB) system. For the DFB steam gasification used for the thermochemical conversion of biomass the bed material cycle rate is a crucial value, which directly influences the heat integration of the process. Unfortunately, in many cases it is complex to measure the entrainment of a hot fluidized bed directly. Thus, several methods can be found in literature to determine the entrainment of a fluidized bed [1-4]. However, many of them are costly or complex to handle, such as computational particle fluid dynamics (CPFD) [5,6]. For the so-called sorption enhanced reforming (SER) process displayed in Figure 1 usually mass and energy balances of the process were used to calculate the bed material cycle rate.

The SER process is an advancement of the conventional DFB gasification [7-9]. A steamblown gasification reactor and an air-blown combustion reactor are the main parts for the SER process. The combustion reactor provides the necessary heat for the overall endothermic steam gasification via combustion of residual char from gasification. At SER conditions, the mass flow of this char to the combustion reactor is typically high enough to produce heat for the overall process. The produced heat is transferred to the gasification reactor via the bed material, which is typical for fluidized beds. Usually silica sand or olivine [10-12] are used for conventional gasification applications as bed material. For the SER process limestone is used. Limestone in combination with comparably low gasification temperatures $\left(600^{\circ} \mathrm{C}\right.$ to

*Corresponding Author: josef.fuchs@tuwien.ac.at 


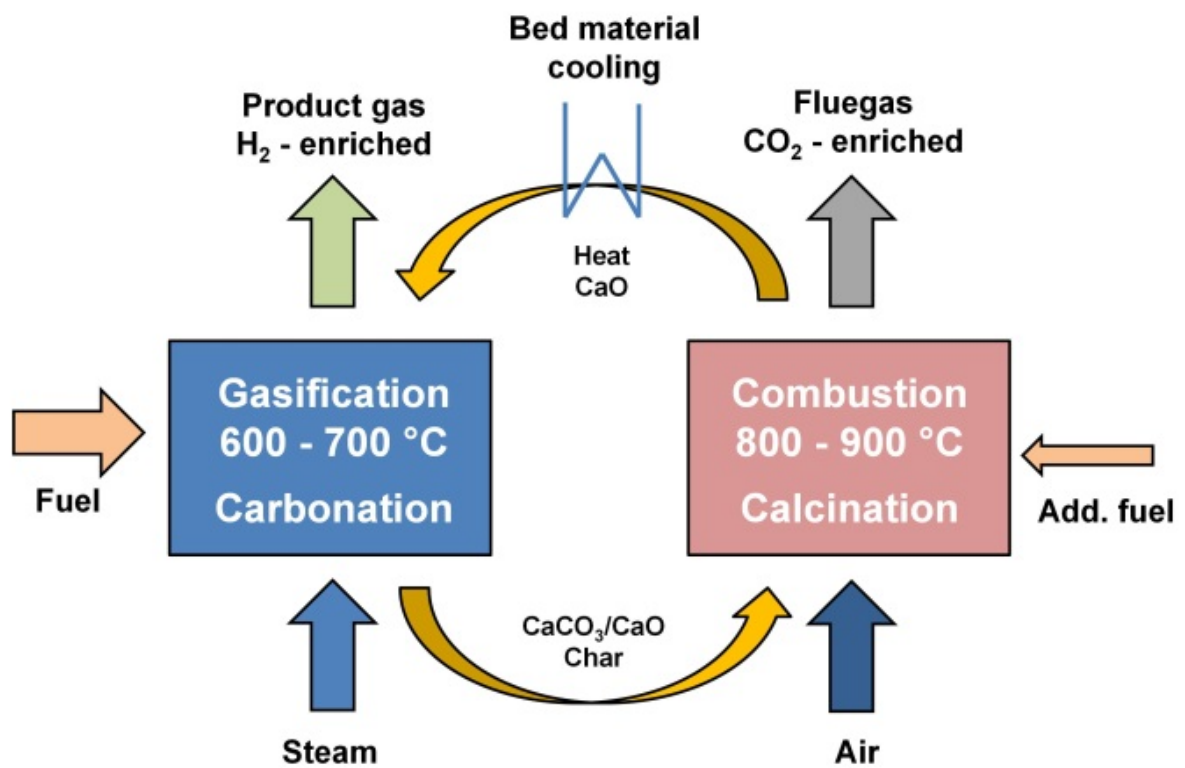

Figure 1: Principle of sorption enhanced reforming (SER) of solid fuels

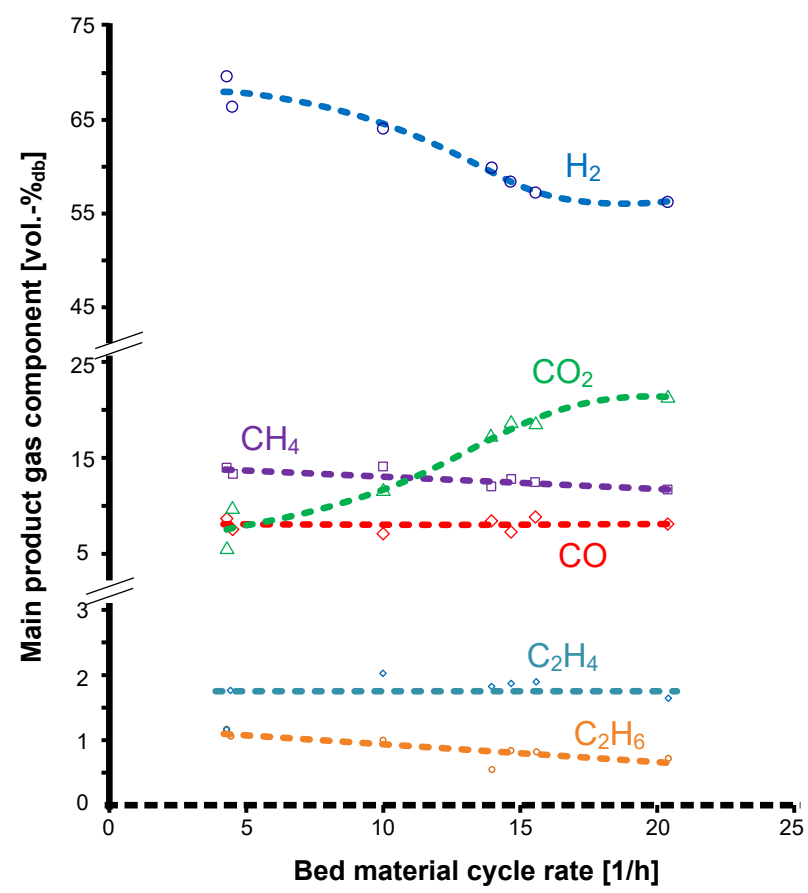

Figure 2: Main product gas composition for the SER process over bed material cycle rate (modified and extended from [15]) 
$700^{\circ} \mathrm{C}$ ) allows for the selective removal of $\mathrm{CO}_{2}$ in the gasification reactor and for the release of the $\mathrm{CO}_{2}$ in the combustion reactor again. Since the water-gas shift reaction is one of the governing homogeneous gas-gas reactions for steam gasification, the removal of $\mathrm{CO}_{2}$ leads to a significant increase of the $\mathrm{H}_{2}$ content in the product gas due to the principle of Le-Chatelier. Thus, up to 75 vol.- $\%_{\mathrm{db}} \mathrm{H}_{2}$ can be reached within the SER process (typically up to $45 \mathrm{vol} .-\%_{\mathrm{db}}$ $\mathrm{H}_{2}$ for conventional DFB gasification). Two main influencing factors have been identified influencing the product gas composition: gasification temperature and bed material cycle rate (displayed in Figure 2) [13]. Since the bed material cycle rate cannot be measured easily in a DFB system, mass and energy balances based on [14] were used to calculate the cycle rate. However, the calculated bed material cycle rate has never been critically reviewed before. Therefore, experimental cold flow investigations were conducted within two different plants. Further a model was developed to be able to calculate the solid entrainment from the combustion reactor also under hot conditions and critically review the results gained from mass and energy balances.

\section{METHODOLOGY}

\subsection{Plant Designs}

Investigations were carried out with two different facilities: An acrylic glass cold flow model and a metallic pilot plant. Firstly, the cold flow model was used to determine the entrainment from the modelled combustion reactor, called "riser" further on in this work. A picture, a sketch and a computational particle fluid dynamics (CPFD) model of the cold flow model can be found in Figure 3. The riser is colored red in the sketch. The model is made of acrylic glass, which allows for visual observation of the processes. The whole acrylic glass model is operated with air under ambient conditions. For all presented calculations $20^{\circ} \mathrm{C}$ and $1 \mathrm{~atm}$ is assumed. Although the model consists of two reactors, two gravity seperators and two cyclones, investigations focus solely on the entrainment of the $1.65 \mathrm{~m}$ high riser with an inner diameter of $52 \mathrm{~mm}$. Experiments were carried out with bronze as bed material due to similarity rules to the hot test plant. Two different experimental campaigns were considered: One with bronze with a sauter mean diameter of $64 \mu \mathrm{m}$ and another one with bronze with a sauter mean diameter of $79 \mu \mathrm{m}$.

As a second plant the metallic hot pilot plant was operated under cold (ambient) conditions as well (Figure 4). In this case the height of the riser is about $4.73 \mathrm{~m}$ and the inner diameter is $125 \mathrm{~mm}$. Geometries of the acrylic glas model and the pilot plant are similar, especially the orthogonally placed outlet of the riser has to be mentioned. Both plants are equipped with a staged air input into the riser: Air can be introduced into the riser at two different heights at the acrylic glass model and at three different heights at the metallic pilot plant. This allows for an effective control of the entrainment: By leaving the total amount of inserted air constant, but changing the ratio of introduced air between the different heights the entrainment can be influenced. The higher the amount of air at a lower input point, the higher the entrainment and vice versa. One experimental campaign has been conducted with olivine with a sauter mean diameter of $90 \mu \mathrm{m}$. 

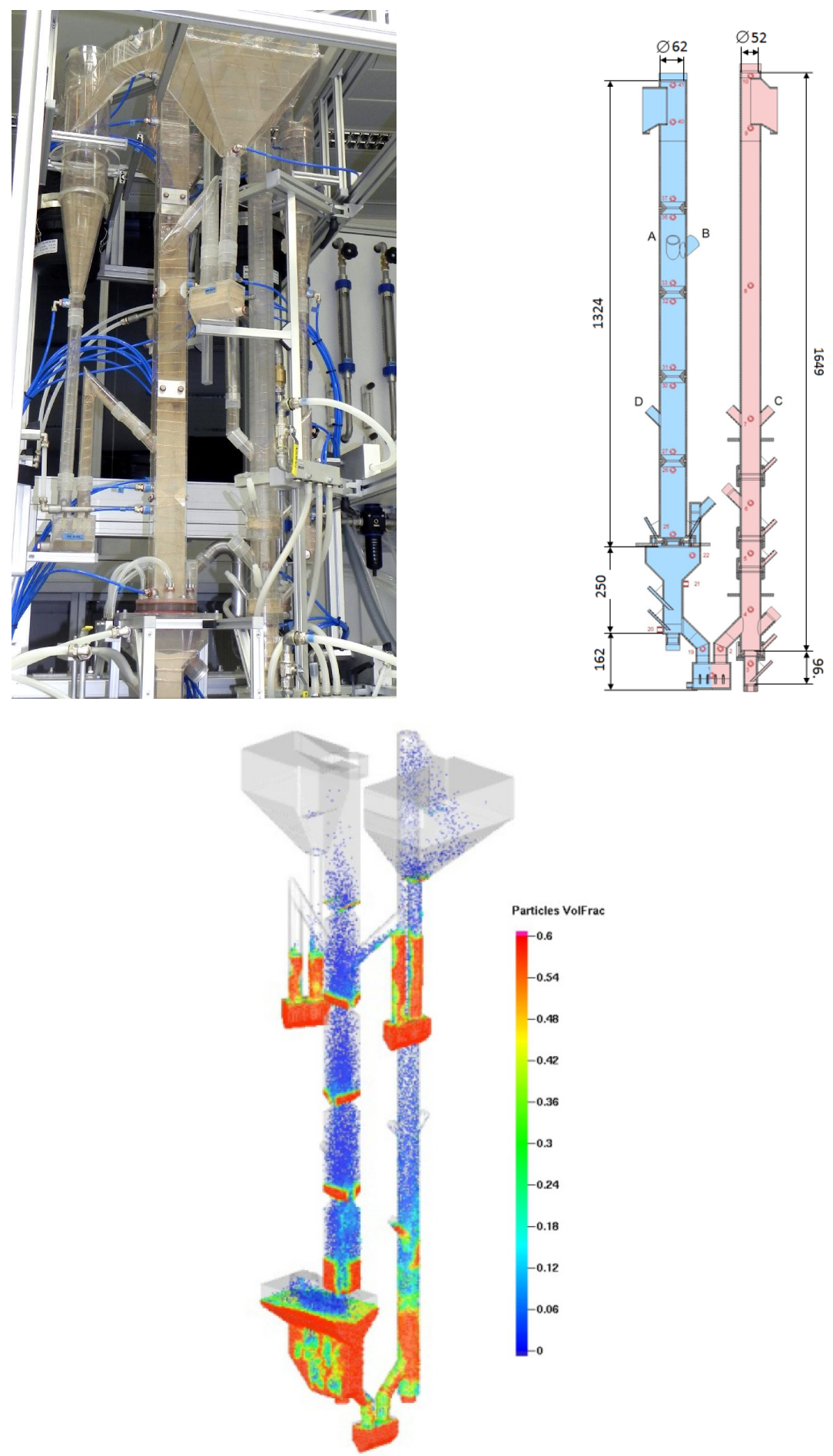

Figure 3: Picture, sketch of the reactors (without separators) and CPFD model [5] of the acrylic glass cold flow model 

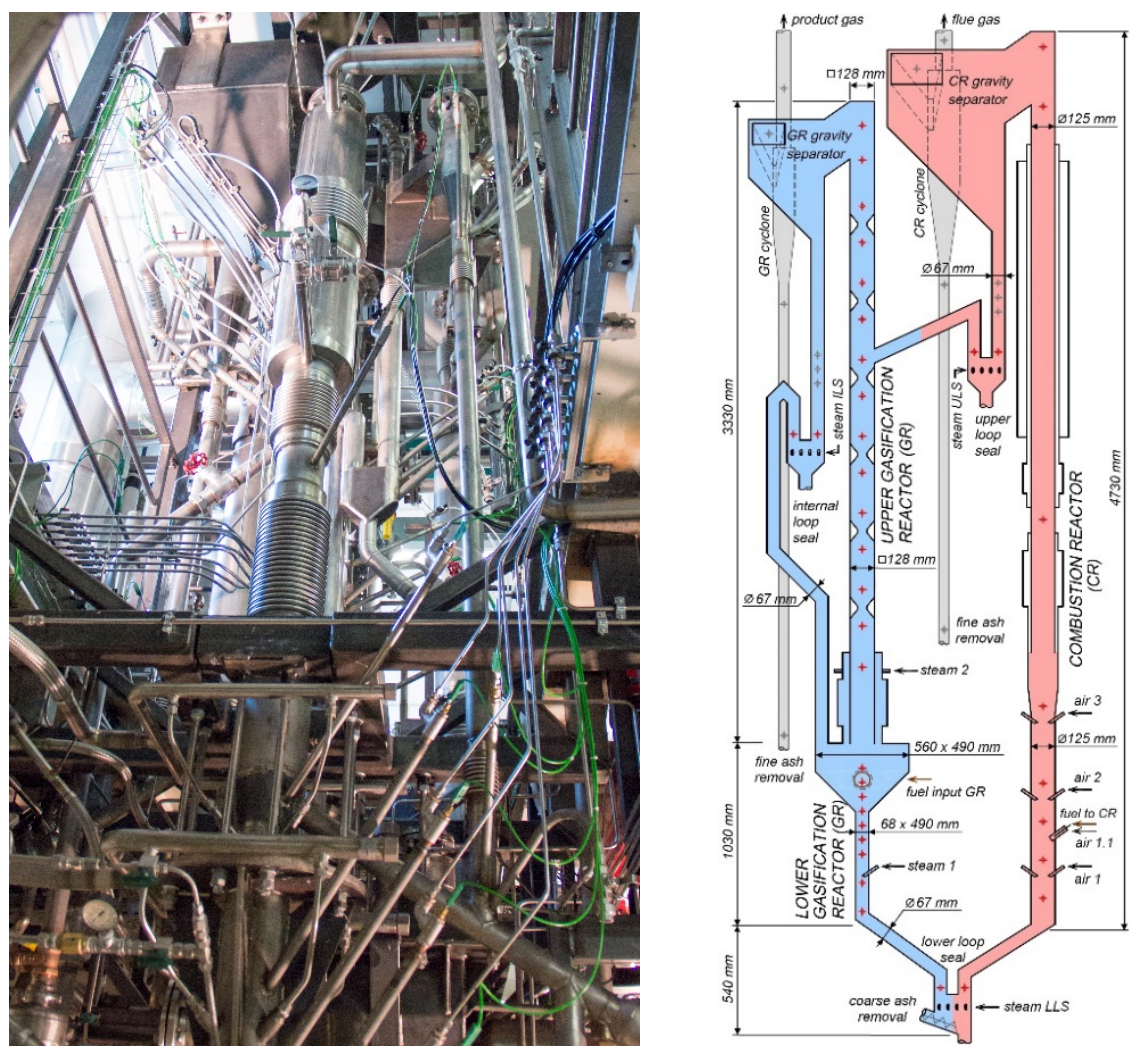

Figure 4: Picture and sketch of the metallic pilot plant (operated as cold flow model for investigations as well)

\subsection{Measurement Methods}

To determine the entrainment of the risers two different methods were used. Since the acrylic glass model is made from a transparent material, an optical method was used (Figure 5): Firstly, the model was turned on (1) and after a steady-state operation was reached, the fluidization of the upper loop seal was turned off abruptly during operation (2). Thus, the bed material transport through the loop seal was blocked and the ascending pipe was filled with bed material. The time, which elapsed until a specific distance of the ascending pipe was filled, was measured (3). Since the bulk density of the bed material and the diameter of the ascending pipe is well-known, the mass of bronze entrained from the riser can be calculated easily. Another method was used for the metallic test plant (Figure 6): Again, the fluidization of the loop seal was turned off abruptly. Then 30 s were measured, while the ascending pipe was filled with bed material (2). When the $30 \mathrm{~s}$ had been elapsed, the fluidization of the riser was turned off abruptly as well (3). Afterwards a vacuum cleaner was used to collect and weigh the olivine in the ascending pipe (4). For this method the position of the opening is of great relevance and should be placed at the same height than the exit pipe of the loop seal is (5). This procedure guaranteed, that only the amount of bed material was collected, which had been filled during the measured 30s. It is assumed that during operation of the system the filling height in the ascending pipe is equal to the exit pipe. 


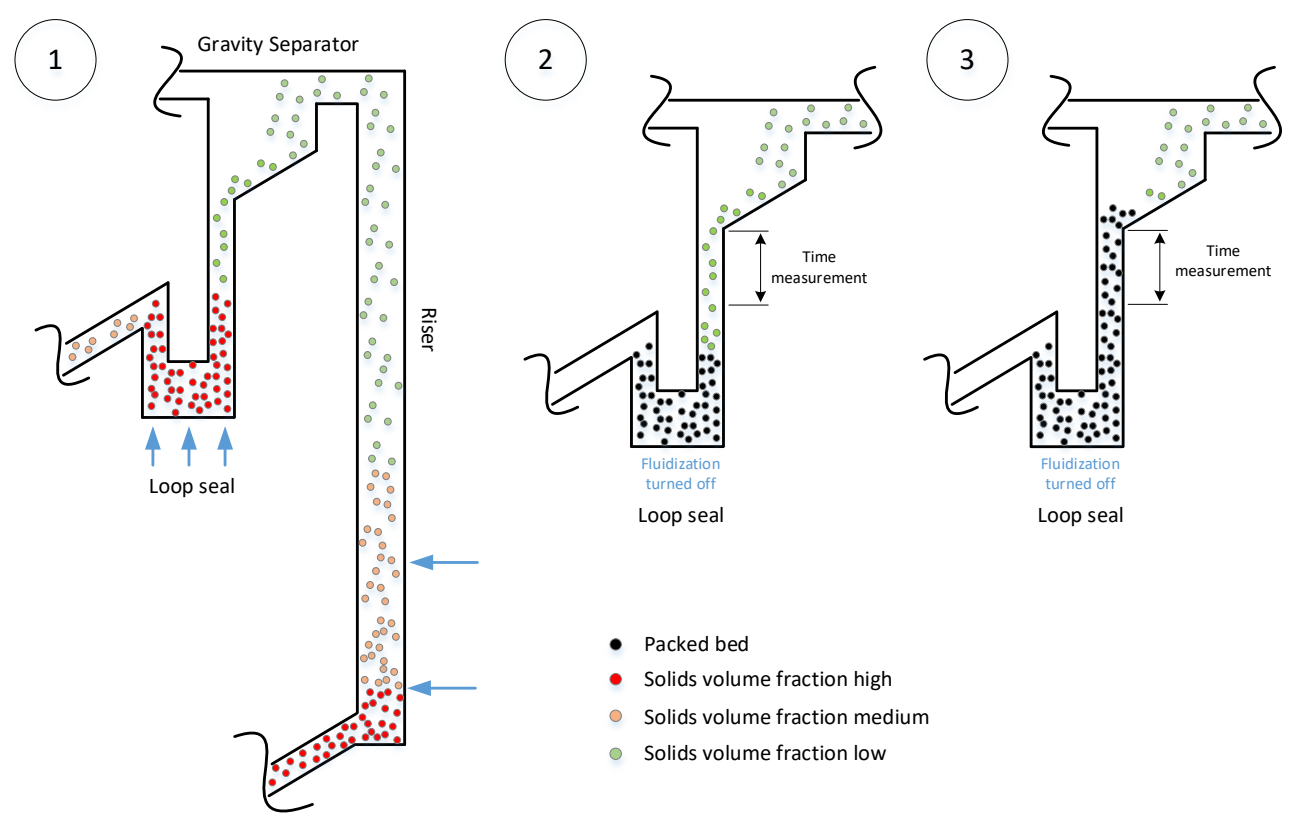

Figure 5: Measurement method of the entrainment of the cold flow mode

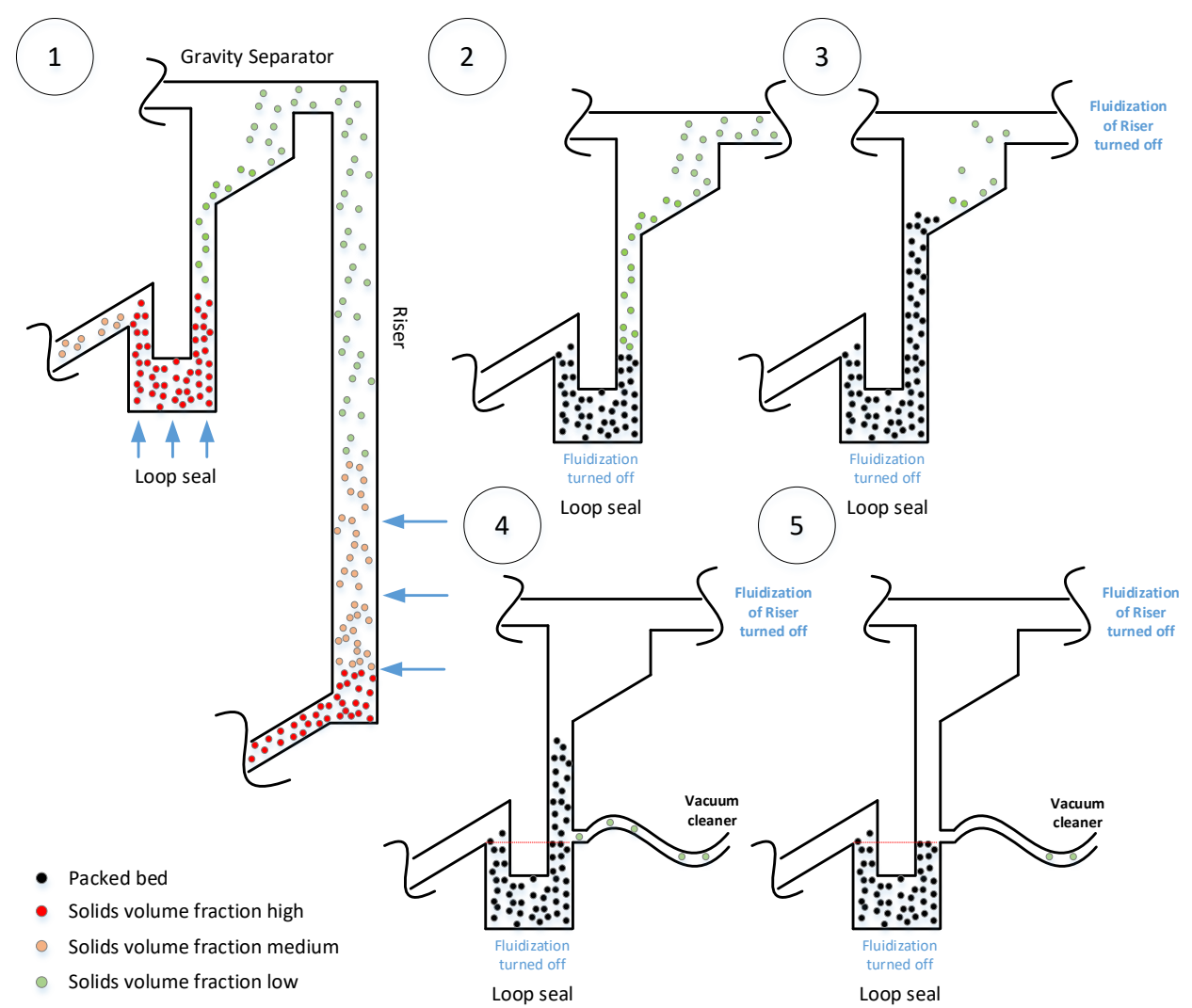

Figure 6: Measurement method of the entrainment of the test plant 


\subsection{Modelling Approach}

To understand the fundamentals of the underlying theory, the fluid dynamics of a fastfluidized bed are of great relevance. Therefore, Figure 7 displays the typical pressure profile and volume fraction of solids in a fast-fluidized bed. A fast-fluidized bed is characterized by a high pressure drop in the lower part of the reactor, where a solids volume fraction is present. However, with increasing height of the reactor a more and more constant pressure drop can be observed. This means, that a nearly constant volume fraction of solids can be found at the upper part of the reactor (upper riser).

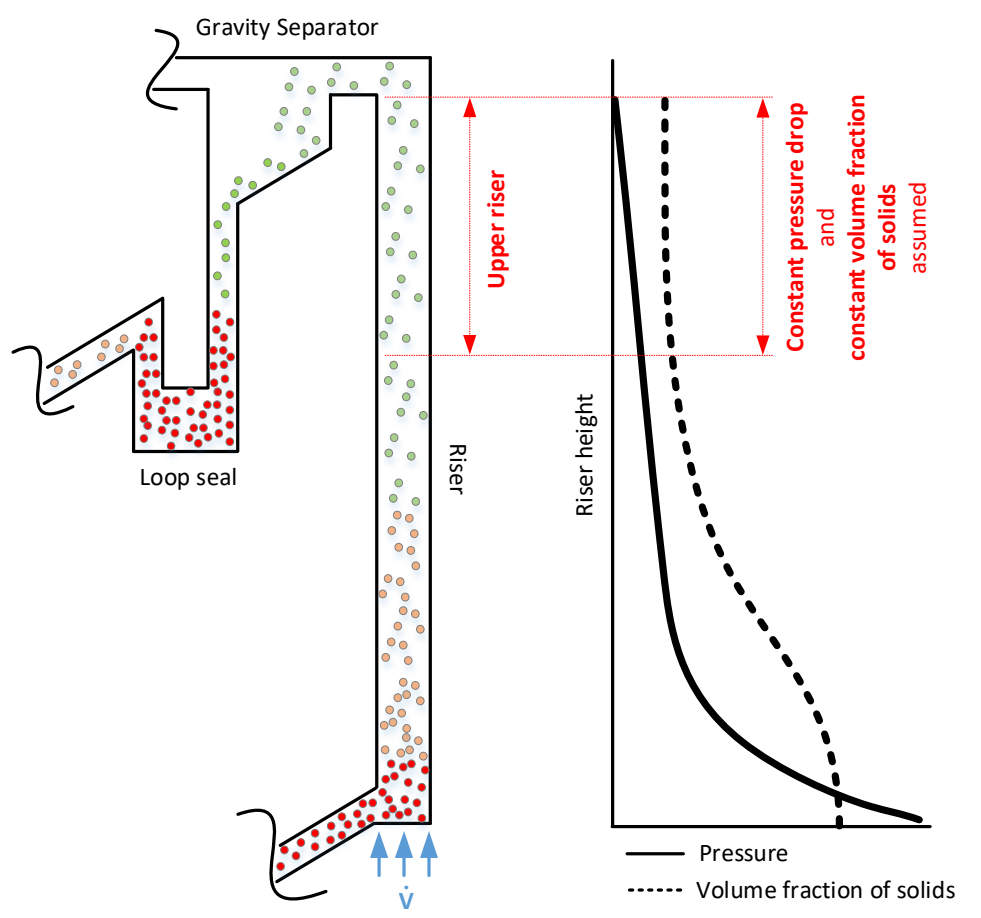

Figure 7: Typical function of pressure and volume fraction of solids over the height of a fast fluidized bed according to $[16,17]$

The assumption of a constant volume fraction of solids in the upper riser and the definition of pressure in a fluidized bed leads to Equation (1). Hereby the (static) pressure drop in the upper part of the reactor $\boldsymbol{\Delta} \boldsymbol{p}_{\text {upper Riser }}$ can be measured, while the cross-sectional area $\boldsymbol{A}$ of the reactors is well-known. Thus, the mass of bed material $\boldsymbol{m}_{\text {upper Riser }}$, which is located in the upper riser, can be calculated. A loading of bed material per volume $\boldsymbol{X}$ can be derived now according to Equation (2). By assuming that this loading is transported with the volume flow of the gas stream the final Equation (3) for the entrainment of the bed material $\dot{\boldsymbol{m}}_{\boldsymbol{d p} / \boldsymbol{d H}}$ is calculated. Acceleration forces are neglected within this simplified approach. This means, that particles are assumed to only move in the upward direction.

$$
\Delta \boldsymbol{p}_{\text {upper Riser }}=\boldsymbol{F} / \boldsymbol{A}=\boldsymbol{M}_{\text {upper Riser }} * \boldsymbol{g} / \boldsymbol{A} \quad \mathrm{Pa}
$$




$$
\begin{array}{cr}
\boldsymbol{X}=\boldsymbol{M}_{\text {upper Riser }} / \boldsymbol{V}_{\text {upper Riser }}=\frac{\Delta \boldsymbol{p}_{\text {upper Riser }}}{\Delta \boldsymbol{H}_{\text {upper Riser } * \boldsymbol{g}}} & \mathrm{kg} / \mathrm{m}^{3} \\
\dot{\boldsymbol{m}}_{\boldsymbol{d p} / \boldsymbol{d H} \boldsymbol{H}}=\boldsymbol{X} * \frac{\dot{\boldsymbol{V}}}{\boldsymbol{A} * 3600} & \mathrm{~kg} /\left(\mathrm{s}^{*} \mathrm{~m}^{2}\right)
\end{array}
$$

\section{RESULTS AND DISCUSSION}

All together 25 different experiments were conducted with the two different plants. 17 of the 25 test runs were cold test runs, where the bed material entrainment was measured directly as described in Figure 5 and Figure 6. Results of these cold test runs can be found in Table 1 Experiment number 1.1a to 2.10. For the hot test runs with the metallic pilot plant (Table 1 Experiment number 3.1 to 3.8 ) the measurement methods for the solids entrainment presented in Figure 5 and Figure 6 are not applicable. The only information about the solids entrainment (or bed material cycle rate) of the riser in the system can be gained by mass and energy balances. The calculation of the bed material entrainment in the mass and energy balance is based on the temperature levels in the gasification reactor and combustion reactor on the one hand and on the energy demand of the gasification reactions on the other hand. By investigating Table 1 in detail, it turns out that the measured entrainment ( $\dot{\boldsymbol{m}}_{\boldsymbol{m e a s}}$ and $\left.\dot{\boldsymbol{m}}_{\boldsymbol{M} \& \boldsymbol{E}}\right)$ and the entrainment $\dot{\boldsymbol{m}}_{\boldsymbol{d} \boldsymbol{p} / \boldsymbol{d} \boldsymbol{H}}$ show significant differences. The measured entrainment is always lower than $\dot{\boldsymbol{m}}_{\boldsymbol{d} \boldsymbol{p} / \boldsymbol{d} \boldsymbol{H}}$. This behavior is typical for riser geometries with an orthogonally located exit. Riser exit geometries with a smoother exit geometry tend to a lower mismatch between the measured and calculated entrainment. The reason for this behavior is described by Stollhof et al. [18] in more detail: It is associated with the reflection of particles at the top of the riser. Particles, which do not reach the exit of the riser, because they cannot follow the gas flow are reflected and are sliding back down near to the wall of the riser. However, the proposed model does not take into account that bed material particles are moving in the opposite direction of the flow, but rather assumes that all particles are moving upwards in direction of the flow. Thus, the calculation method is a measure for the maximum expectable entrainment. To further investigate the mismatch between these values, the key figure $\boldsymbol{R}$ is introduced (Equation 4). It simply is the ratio of actually measured entrainment ( $\dot{\boldsymbol{m}}_{\boldsymbol{m} \text { eas }}$ and $\dot{\boldsymbol{m}}_{\boldsymbol{M} \& \boldsymbol{E}}$ ) to theoretically calculated entrainment $\dot{\boldsymbol{m}}_{\boldsymbol{d p} / \boldsymbol{d H}}$.

$$
R=\dot{m}_{m e a s} / \dot{m}_{d p / d H} ; R=\dot{m}_{M \& E} / \dot{m}_{d p / d H}
$$

A ratio of 0.16 to 0.24 can be found for the cold flow model investigations (Experiment number 1.1 a to $1.7 \mathrm{~b}$ ) and shows that between $16 \%$ and $24 \%$ of the theoretically calculated mass are leaving the riser really. Surprisingly, $\boldsymbol{R}$ is in a narrow range for the cold flow model investigations, but seems to decrease slightly with increasing pressure gradient of the upper riser. Similar results can be found for the experiments with the pilot plant: This is not straightforward for two reasons: On the one hand, the measurement method of the entrainment is completely different. For the cold test runs (experiments number 2.1 to 2.10) the entrainment was measured directly according to Figure 6, whereas for the hot test runs (experiments number 3.1 to 3.8 ) the determination of the entrainment of the riser is only possible indirectly by mass and energy balances. On the other hand, the operation conditions of the riser for both cases were completely different as well: Two different bed materials were used (olivine $90 \mu \mathrm{m}$ vs. two different limestones $290 \mu \mathrm{m}$ and $480 \mu \mathrm{m}$ ) and the applied temperatures were different. Thus, the characteristics of the fluid are affected directly 
(e.g. density, viscosity). However, a detailed investigation of the correlations of $\boldsymbol{R}$ between pressure gradient and entrainment shows, that $\boldsymbol{R}$ seems to be related mainly to the pressure gradient in the upper riser (see Figure 8). In general, $\boldsymbol{R}$ is a bit lower for the cold test run. It is likely that a systematic error, caused by one of the different measurement methods, leads to the deviation. Nevertheless, an empirical equation for $\boldsymbol{R}$, that fits both datasets satisfactory, is proposed in Equation (5).

$$
\begin{gathered}
R_{\text {calc }}=7.364 E-1 *(\Delta p / \Delta H)^{-1.74 E-1} \\
\dot{m}_{\text {calc }}=\frac{\Delta p_{\text {upper Riser } * \dot{V}}}{\Delta H_{\text {upper Riser } * g}} \frac{1}{A * 3600} * R_{\text {calc }} \quad \mathrm{kg} /\left(\mathrm{s}^{*} \mathrm{~m}^{2}\right)
\end{gathered}
$$
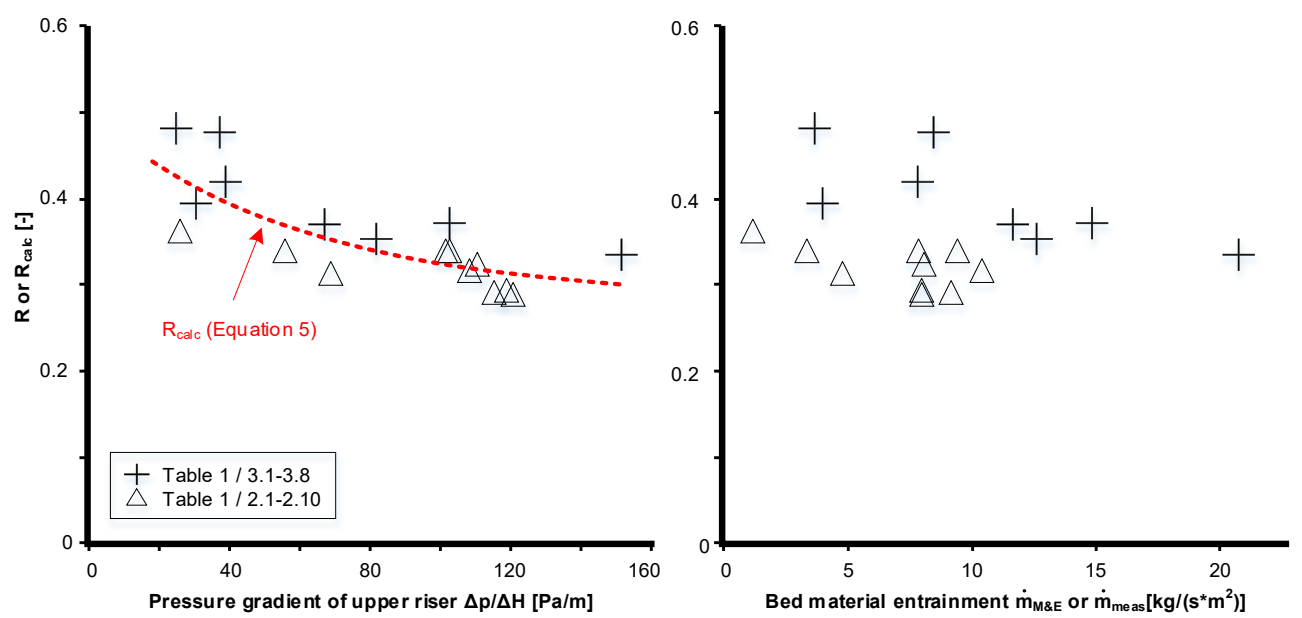

Figure 8: Ratio of measured to calculated entrainment in dependency of the pressure gradient in the upper riser and the bed material entrainment of the metallic pilot plant
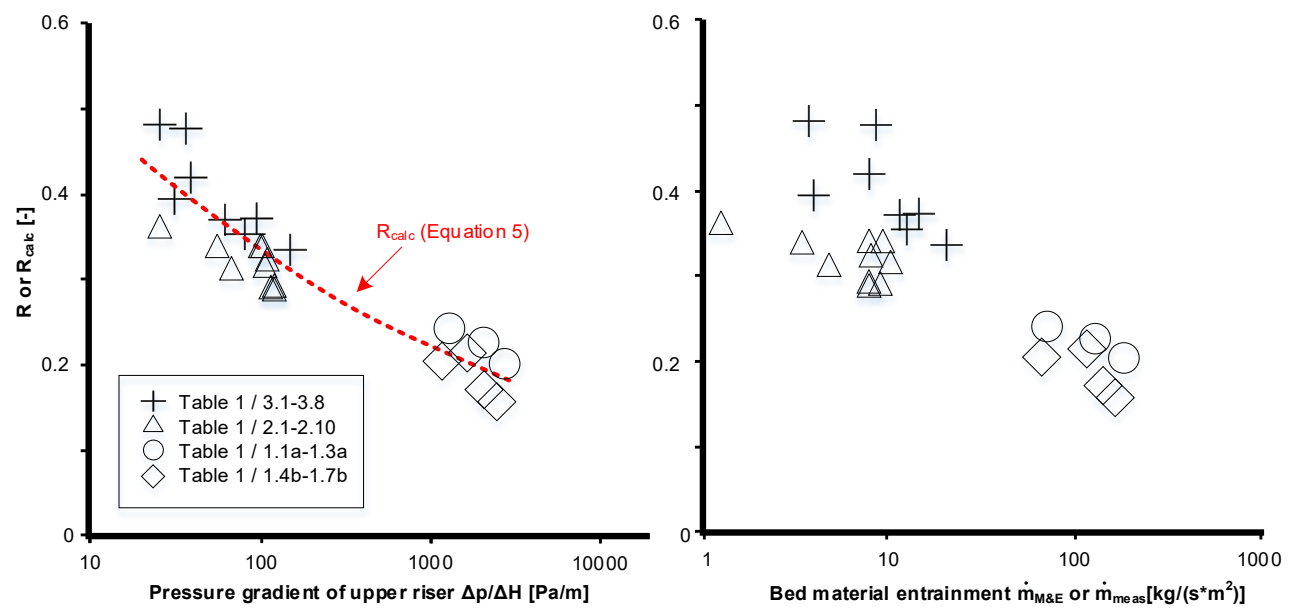

Figure 9: Ratio of measured to calculated entrainment in dependency of the logarithmic pressure gradient in the upper riser and the bed material entrainment of the whole dataset presented in Table 1 


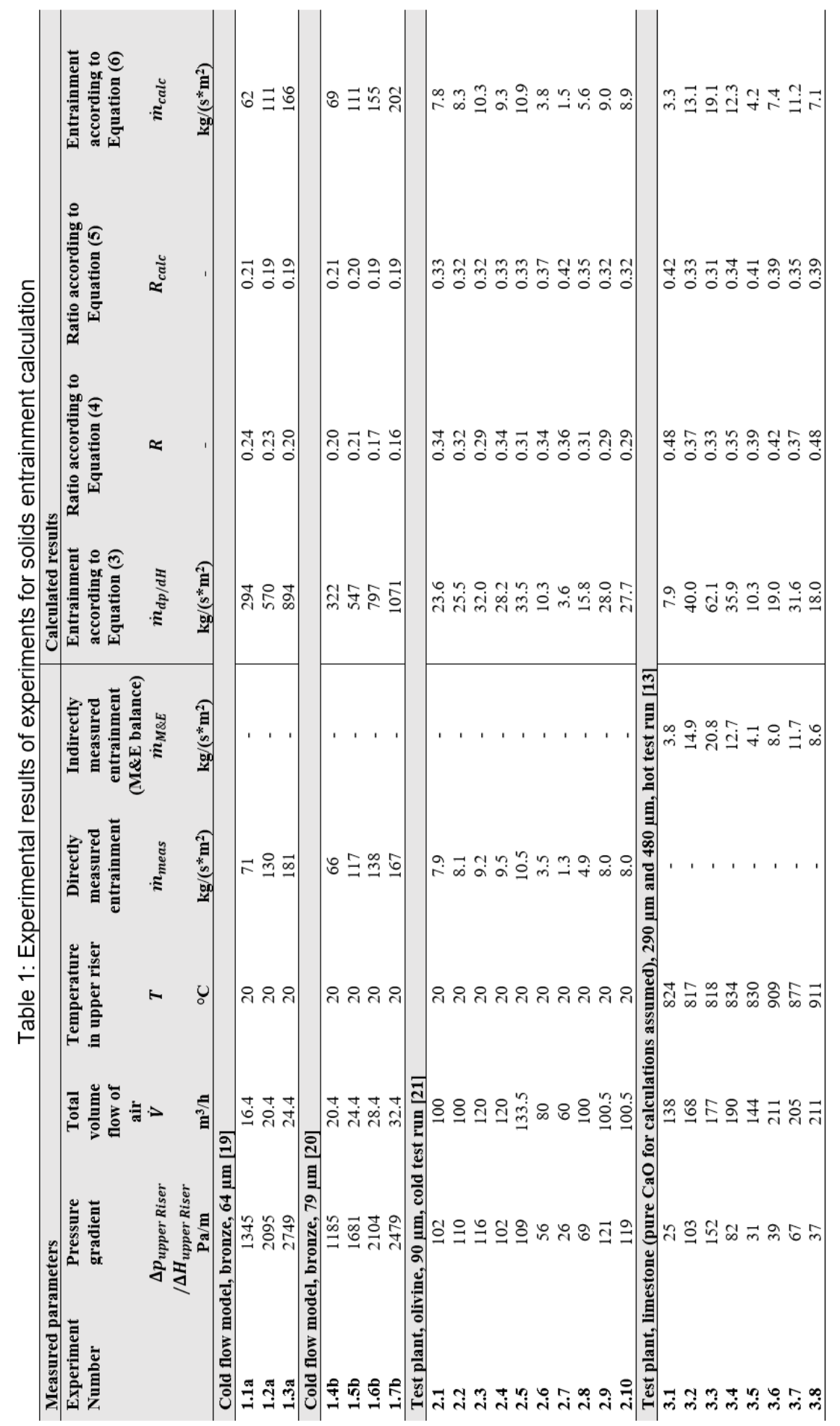


Equation 5 can be seen as characteristic correlation for the test plant and its geometry. However, it allows for the prediction of plants with similar geometries (especially orthogonally located exit of the riser) as well. This assumption can be proven by applying Equation 5 to the full dataset presented in Table 1, which includes experiments of the cold flow model as well. As shown in Figure 9, Equation 5 is also applicable for the cold flow model. The full equation for the prediction of the solids entrainment $\dot{\boldsymbol{m}}_{\text {calc }}$ of a riser with orthogonally placed exit is given in Equation 6.

\section{CONCLUSION}

To determine the entrainment of a fluidized bed under hot conditions, it is not necessary to conduct direct mass flow measurements at the hot plant itself. Investigations can be done easily under cold conditions. Classic scaling criteria for fluidized beds [17,22-25] were not taken into account. The proposed method is basically independent from these criteria. Not even the same plant (size) is required, but geometric similarity, especially regarding riser exit geometry, is mandatory. Since the riser geometry with an orthogonally placed exit is not suitable for an ideal approach as proposed in Equation 1 to Equation 3, the correction factor $\boldsymbol{R}$ must be introduced. The idea of this factor is to compensate for non-ideal behavior because of particles, which are reflected and do not leave the riser exit. Unfortunately, the factor $\boldsymbol{R}$ is not constant, but dependent on the pressure gradient of the upper part of the riser. Since a broad range of bed materials has been investigated, a general equation for the factor $\boldsymbol{R}_{\text {calc }}$ and the specific geometry has been found. Thus, the prediction of the solids entrainment of the investigated riser geometry is possible via Equation 6: With the knowledge of the easily measureable pressures along the upper part of the riser and the consideration of the correction factor $\boldsymbol{R}_{\text {calc }}$ the mass flow can be calculated in a narrow deviation to the real mass flow. Further, for the dual fluidized bed gasification and the sorption enhanced reforming process it has been proven that the determination of the bed material cycle rate, which is closely linked to the riser entrainment, can be done accurately via mass and energy balance.

\begin{tabular}{|c|c|}
\hline \multicolumn{2}{|c|}{ SYMBOLS } \\
\hline$\dot{m}_{M \& E}$ & $\begin{array}{l}\text { Indirectly measured entrainment from the riser via mass and } \\
\text { energy balance in } \mathrm{kg} /\left(\mathrm{s}^{*} \mathrm{~m}^{2}\right)\end{array}$ \\
\hline$\dot{m}_{\text {calc }}$ & $\begin{array}{l}\text { Calculated actual entrainment from the riser with factor } \\
\boldsymbol{R}_{\boldsymbol{c}} \text { in } \mathrm{kg} /\left(\mathrm{s}^{*} \mathrm{~m}^{2}\right)\end{array}$ \\
\hline$\dot{\boldsymbol{m}}_{d p / d H}$ & $\begin{array}{l}\text { Calculated maximum possible entrainment from the riser in } \\
\mathrm{kg} /\left(\mathrm{s}^{*} \mathrm{~m}^{2}\right)\end{array}$ \\
\hline$\dot{m}_{\text {meas }}$ & Actually measured entrainment in $\mathrm{kg} /\left(\mathrm{s}^{*} \mathrm{~m}^{2}\right)$ \\
\hline$\dot{V}$ & $\begin{array}{l}\text { Volume flow of air used for fluidizing the riser in actual } \mathrm{m}^{3} / \mathrm{h} \\
\text { (temperature and pressure at the upper part of the riser) }\end{array}$ \\
\hline$M_{\text {upper Riser }}$ & $\begin{array}{l}\text { Mass of bed material which is located between the measuring } \\
\text { points of } \Delta \boldsymbol{p} \text { in } \mathrm{kg}\end{array}$ \\
\hline $\boldsymbol{R}_{\text {calc }}$ & Empirical equation for $\boldsymbol{R}$ dependent from $\Delta \boldsymbol{\Delta} / \boldsymbol{\Delta} \boldsymbol{H}$ \\
\hline$V_{\text {upper Riser }}$ & Geometrical volume in between the measuring points of $\Delta p$ in $\mathrm{m}^{3}$ \\
\hline$A$ & Cross sectional area of the upper riser in $\mathrm{m}^{2}$ \\
\hline $\boldsymbol{F}$ & Force in $\mathrm{kg} * \mathrm{~m} / \mathrm{s}^{2}$ \\
\hline $\boldsymbol{R}$ & $\begin{array}{l}\text { Ratio between directly measured entrainment } \dot{\boldsymbol{m}}_{\text {meas }} \text { or indirectly } \\
\text { measured entrainment } \dot{\boldsymbol{m}}_{\boldsymbol{M} \& \boldsymbol{E}} \text { and calculated entrainment } \dot{\boldsymbol{m}}_{\text {calc }}\end{array}$ \\
\hline
\end{tabular}




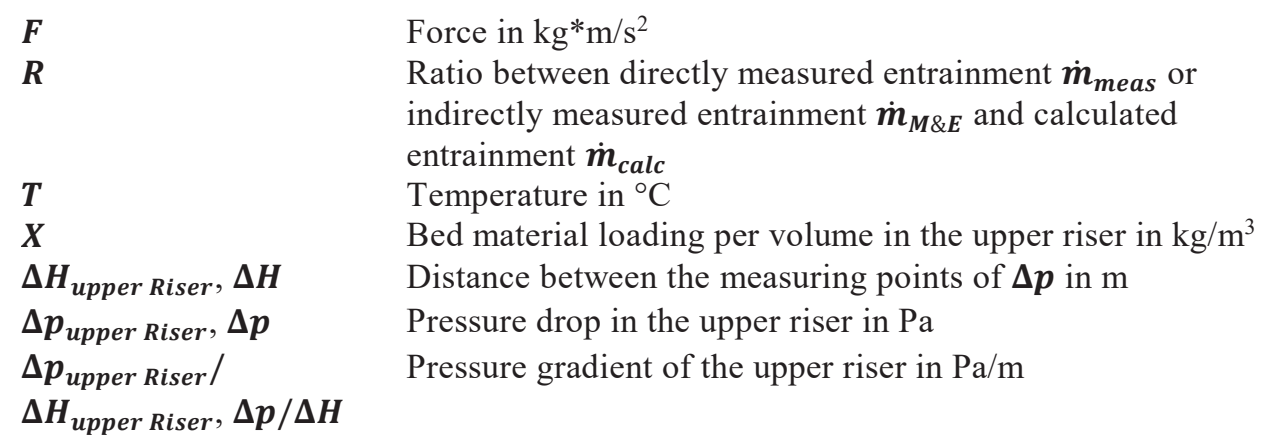

\section{REFERENCES}

[1] Bhusarapu S, Fongarland P, Al-Dahhan MH, Duduković MP. Measurement of overall solids mass flux in a gas-solid Circulating Fluidized Bed. Powder Technol [Internet]. 2004 Nov 11 [cited 2018 Oct 28];148(2-3):158-71.

[2] Matsuda S. Measurement of solid circulation rate in a circulating fluidized bed. Powder Technol [Internet]. 2008 Oct 28 [cited 2018 Oct 28];187(2):200-4.

[3] Ludlow JC, Monazam ER, Shadle LJ. Improvement of continuous solid circulation rate measurement in a cold flow circulating fluidized bed. Powder Technol [Internet]. 2008 Mar 10 [cited 2018 Oct 28];182(3):379-87.

[4] Medrano JA, Nordio M, Manzolini G, van Sint Annaland M, Gallucci F. On the measurement of solids circulation rates in interconnected fluidized beds: Comparison of different experimental techniques. Powder Technol [Internet]. 2016 Nov 1 [cited 2018 Oct 28];302:81-9.

[5] Lunzer A. CPFD simulation in Barracuda VR of a novel dual fluid bed cold flow model. TU Wien, Master Thesis; 2018.

[6] Kraft S. Investigation of particle mixing in dual fluidized bed gasification systems by means of cold flow modelling and computational methods. TU Wien, PhD Thesis; 2017.

[7] Benedikt F, Schmid JC, Fuchs J, Mauerhofer AM, Müller S, Hofbauer H. Fuel flexible gasification with an advanced $100 \mathrm{~kW}$ dual fluidized bed steam gasification pilot plant. Energy [Internet]. 2018;164:329-43.

[8] Mauerhofer AM, Benedikt F, Schmid JC, Fuchs J, Müller S, Hofbauer H. Influence of Different Bed Material Mixtures on Dual Fluidized Bed Steam Gasification. Energy [Internet]. 2018;157.

[9] Benedikt F, Fuchs J, Schmid JC, Müller S, Hofbauer H. Advanced dual fluidized bed steam gasification of wood and lignite with calcite as bed material. Korean J Chem Eng. 2017;34(7):1-11.

[10] Kuba M, Kirnbauer F, Hofbauer H. Influence of coated olivine on the conversion of intermediate products from decomposition of biomass tars during gasification. Biomass Convers Biorefinery [Internet]. 2016

[11] Kuba M, Havlik F, Kirnbauer F, Hofbauer H. Influence of bed material coatings on the water-gas-shift reaction and steam reforming of toluene as tar model compound of biomass gasification. Biomass and Bioenergy [Internet]. 2015;1-10. 
[12] Koppatz S, Pfeifer C, Hofbauer H. Comparison of the performance behaviour of silica sand and olivine in a dual fluidised bed reactor system for steam gasification of biomass at pilot plant scale. Chem Eng J [Internet]. 2011;175(1):468-83.

[13] Fuchs J, Schmid JC, Benedikt F, Müller S, Hofbauer H, Stocker H, et al. The impact of bed material cycle rate on in-situ $\mathrm{CO} 2$ removal for sorption enhanced reforming of different fuel types. Energy [Internet]. 2018;162:35-44.

[14] Pröll T, Hofbauer H. Development and Application of a Simulation Tool for Biomass Gasification Based Processes. Int J Chem React Eng. 2008;6:Article A89.

[15] Schmid JC, Fuchs J, Benedikt F, Mauerhofer AM, Müller S, Hofbauer H, et al. Sorption Enhanced Reforming with the Novel Dual Fluidized Bed Test Plant at TU Wien. In: European Biomass Conference and Exhibition (EUBCE). Stockholm; 2017. p. 421-8.

[16] Kunii D, Levenspiel O. Fluidization engineering, 2nd edition. Stoneham, MA (United States); Butterworth Publishers; 1991.

[17] Grace J, Knowlton T, Avidan A. Circulating Fluidized Beds. 1997.

[18] Stollhof M, Penthor S, Mayer K, Hofbauer H. Estimation of the solid circulation rate in circulating fl uidized bed systems. Powder Technol [Internet]. 2018;336:1-11.

[19] Fuchs J. Ermittlung des Betriebskennfeldes einer innovativen Zweibettwirbelschicht anhand von Kaltmodelluntersuchungen. MU Leoben, Master Thesis; 2013.

[20] Martinovic D. Kaltmodellversuche und MSR-Konzept einer Zweibett-WirbelschichtVergasungsanlage. TU Wien, Master Thesis; 2013.

[21] Bickel AA. Untersuchungen zu den Scalingkriterien an einer Zweibett-WirbelschichtVergasungsanlage. TU Wien, Master Thesis; 2018.

[22] Glicksman LR, Hyre MR, Farrell PA. Dynamic similarity in fluidization. Int J Multiph Flow [Internet]. 1994 Aug 1 [cited 2018 Oct 21];20:331-86.

[23] Glicksman LR, Hyre M, Woloshun K. Simplified scaling relationships for fluidized beds. Powder Technol [Internet]. 1993 Nov 1 [cited 2018 Oct 21];77(2):177-99.

[24] Reh L. Das Wirbeln von körnigem Gut in schlanken Diffusoren als Grenzzustand zwischen Wirbelschicht und pneumatischer Förderung. TH Karlsruhe, PhD Thesis; 1961.

[25] Bi HT, Grace JR. Flow regime diagrams for gas-solid fluidization and upward transport. Int J Multiph Flow [Internet]. 1995 Nov 1 [cited 2018 Oct 21];21(6):1229-36. 
